\title{
Nitroalkane anomaly: computational study with cluster and continuum modeling
}

\author{
Hiroshi Yamataka* and Salai Cheettu Ammal \\ Institute of Scientific and Industrial Research, Osaka University, Ibaraki, Osaka, 567-0047 Japan \\ E-mail: yamataka@sanken.osaka-u.ac.jp
}

Dedicated to Prof. Roberto A. Rossi and Prof. Edmundo Rúveda

(received 03 Jun 03; accepted 18 Jul 03; published on the web 23 Jul 03)

\begin{abstract}
The origin of anomalous relation between rates and equilibria for the proton-transfer reactions of nitroalkanes, known as nitroalkane anomaly, was investigated by theoretical calculations with a cluster model, in which three water molecules are explicitly considered in the system, as well as the PCM solvent continuum model. For the $\mathrm{CH}_{3} \mathrm{NO}_{2} / \mathrm{CH}_{3} \mathrm{CH}_{2} \mathrm{NO}_{2}$ system, B3L YP and MP2 computations reproduced the anomaly, and the imbalance in the charge distribution at the transition state (TS) was observed. In contrast, although the TS imbalance was detected for the substituted phenylnitromethane system, the Brønsted plots did not show any anomaly. The experimentally observed abnormally large Brønsted coefficient ( $\alpha \sim 1.4$ ) for this system does not arise from the charge imbalance at the saddle point structure, but is likely due to the effect of the reaction dynamics.
\end{abstract}

Keywords: Nitroalkane anomaly, Brønsted plot, theoretical calculations, transition state

\section{Introduction}

Pearson and Dillon reported in 1953 that logarithmic plots of deprotonation rate constants of various carbon acids against corresponding equilibrium constants gave linear Brønsted plots with the slope of about 0.5 and that the points of $\mathrm{CH}_{3} \mathrm{NO}_{2}$ and $\mathrm{CH}_{3} \mathrm{CH}_{2} \mathrm{NO}_{2}$ deviated downwards by more than $2 \log$ units. ${ }^{1}$ The slower than expected rates for these nitroalkanes were rationalized in terms of charge localization of the anion species. Thus, in the anion species (1), the negative charge was considered to almost completely be localized on the nitro function, which slowed down the rate of protonation from any proton source to this anion. In other words, the anion is stabilized by the electronic shift from $\mathrm{CH}_{2}$ to $\mathrm{NO}_{2}$, which takes place after deprotonation. 


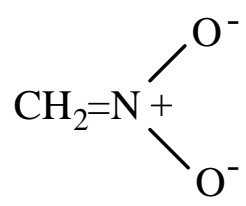

Similar anomalous behavior of the nitro substituent in the proton-transfer reactions of nitroalkanes and other reactions has been reported. ${ }^{2,3}$ In a typical example, the $\mathrm{p} K_{\mathrm{a}}$ value of $\mathrm{RCH}_{2} \mathrm{NO}_{2}$ decreases in the order $\mathrm{CH}_{3} \mathrm{NO}_{2}>\mathrm{CH}_{3} \mathrm{CH}_{2} \mathrm{NO}_{2}>\left(\mathrm{CH}_{3}\right)_{2} \mathrm{CHNO}_{2}$ in water, whereas the rate of proton abstraction by hydroxide ion decreases in the same order. ${ }^{2}$ Here the reaction is slower for a more acidic substrate. The anomaly can be characterized by an abnormal Brønsted coefficient (a slope $\alpha$ outside the range of 0 to 1 ), and the above example gives a negative $\alpha$ value. An analogous system with an electron-withdrawing $\mathrm{CN}$ substituent, i.e., $\mathrm{RCH}_{2} \mathrm{CN}$, exhibits normal rate-equilibrium relationship in water. ${ }^{4}$ For the proton transfer reactions of substituted phenylnitromethanes and 1-phenyl-1-nitroethanes $\left(\mathrm{XC}_{6} \mathrm{H}_{4} \mathrm{CH}_{2} \mathrm{NO}_{2}\right.$ and $\left.\mathrm{XC}_{6} \mathrm{H}_{4} \mathrm{CH}\left(\mathrm{CH}_{3}\right) \mathrm{NO}_{2}\right)$ with a base in aqueous solvent are another well-known abnormal case. ${ }^{3}$ In these reactions, the substituent effect is larger on the rates than on the equilibria, giving $\alpha \sim 1.4$.

These unusual behavior in the rate-equilibrium relationship of nitroalkanes, often called "nitroalkane anomaly" has been reported not only for proton transfer reactions but also for $\mathrm{S}_{\mathrm{N}} 2$ reactions in which the anion acts as a nucleophile. ${ }^{5}$ Thus, a carbanion stabilized by the adjacent $\mathrm{NO}_{2}$ function showed lower nucleophilicity compared to other carbanions in chlorine transfer reactions. The common features in these reactions are that (1) the $\mathrm{NO}_{2}$ function stabilizes the anion very much but does not stabilize the transition state (TS) compared to the anion, and hence (2) the TS is more sensitive to additional stabilization caused by substituents at the carbanion center.

The concept of TS imbalance has been considered to be responsible for the anomaly. ${ }^{2,6,7}$ The TS imbalance assumes that the unit negative charge in the anion product is nearly completely be localized on the $\mathrm{NO}_{2}$ function, whereas a partial negative charge developed within the $\mathrm{RCHNO}_{2}$ moiety at the TS is largely localized on the RCH subgroup due to electrostatic interaction between the negatively charged carbon and the positively charged proton in-flight. Questions arise in two ways. First, does the nitroalkane anomaly arise from the inherent nature of the TS and hence could it be detected by MO/DFT computations of the TS? Second, does the TS charge imbalance indeed operate in the reaction? Here, we report a theoretical study on the proton-transfer reactions of nitroalkanes, which answers these questions.

\section{Computational methods}

$\mathrm{Ab}$ initio $\mathrm{MO}$ and DFT calculations were carried out for the reactions of $\mathrm{CH}_{3} \mathrm{NO}_{2}$ and $\mathrm{CH}_{3} \mathrm{CH}_{2} \mathrm{NO}_{2}$ with $\mathrm{OH}^{-}$(eq 1) at the $\mathrm{HF} / 6-31+\mathrm{G}^{*}$, B3LYP/6-31+G*, MP2/6-31+G*, and 
MP2/6-311+G** levels of theory and for the reactions of substituted phenylnitromethanes (eq 2) at $\mathrm{HF} / 6-31+\mathrm{G}^{*}$ and B3LYP/6-31+G*. ${ }^{8}$ These reactions have previously been found to have no TS in the gas phase since $\mathrm{OH}^{-}$is an extremely strong base when it is unsolvated. ${ }^{7}$ In order to simulate the reactions in aqueous solvents, we used two model systems in the present study. First, we used a cluster model, in which three water molecules were explicitly considered to solvate the base and the nitroalkanes. Second, the effect of bulk solvent was taken into account for the cluster model with the continuum reaction field scheme. Full frequency analyses were carried out to confirm that the optimized structures were minima or saddle points for the cluster model. Solvent effects with the continuum model were evaluated with the united atom topological model optimized for the HF level (UAHF) to build the cavity under the PCM scheme. ${ }^{9}$ The solvation energy (PCM//HF/6-31+G*) was then added to the energy calculated with the cluster model. The purpose of the calculations is not to reproduce the exact activation and reaction energies but to analyze the effect of substituents on nitroalkanes on these quantities. The combined use of the cluster model that takes into account specific solvation and the continuum model that evaluates the effect of bulk solvation would suffice for the purpose.

$$
\begin{gathered}
\mathrm{RCH}_{2} \mathrm{NO}_{2}+\mathrm{OH}^{-} \rightleftharpoons \mathrm{RCHNO}_{2}^{-}+\mathrm{H}_{2} \mathrm{O} \\
\mathrm{R}=\mathrm{H} \text { or } \mathrm{CH}_{3} \\
p-\mathrm{X}_{-} \mathrm{C}_{6} \mathrm{H}_{4} \mathrm{CH}_{2} \mathrm{NO}_{2}+\mathrm{OH}^{-} \rightleftharpoons p-\mathrm{X}_{-} \mathrm{C}_{6} \mathrm{H}_{4} \mathrm{CHNO}_{2}^{-}+\mathrm{H}_{2} \mathrm{O} \\
\mathrm{X}=\mathrm{CH}_{3} \mathrm{O}, \mathrm{H} \text { or } \mathrm{NO}_{2}
\end{gathered}
$$

\section{Results and Discussion}

\section{Reaction of $\mathrm{CH}_{3} \mathrm{NO}_{2} / \mathrm{CH}_{3} \mathrm{CH}_{2} \mathrm{NO}_{2}$}

Figure 1 shows the reaction scheme for $\mathrm{CH}_{3} \mathrm{NO}_{2}$ with the cluster model. Here, $\mathrm{OH}^{-}$is solvated by two water molecules throughout the reaction and the $\mathrm{NO}_{2}$ function is solvated by one water molecule in the reactant complex (cmp1), TS, and product complex (cmp2) states. Table 1 lists the energy variations along the reaction relative to separated reactants calculated with the cluster and the PCM models, together with those for the gas phase reaction reported previously. ${ }^{7}$ As mentioned in a previous report, the reaction of $\mathrm{CH}_{3} \mathrm{NO}_{2}$ with $\mathrm{OH}^{-}$in the gas phase did not give TS due to extremely large exothermicity ( -30 $\mathrm{kcal} \mathrm{mol}^{-1}$ at $\mathrm{MP} 2 / 6-311+\mathrm{G}^{* *}$ ), and therefore calculations were carried out with $\mathrm{CN}^{-}$as a base. ${ }^{7}$ Table 1 shows that the relative activation and reaction energies $\left(\mathrm{CH}_{3} \mathrm{NO}_{2}\right.$ vs. $\left.\mathrm{CH}_{3} \mathrm{CH}_{2} \mathrm{NO}_{2}\right)$ are similar for the B3LYP and the MP2 methods. In all three systems, the reactions followed a double-well potential, as is often assumed for proton-transfer reactions. This is because cmp1, TS, and cmp2 received stabilization from interaction among reacting species, which does not exist in the separated reactants and product 
states. We will focus on the substituent effects on the TS and the product anion because nitroalkane anomaly should relate to these states.

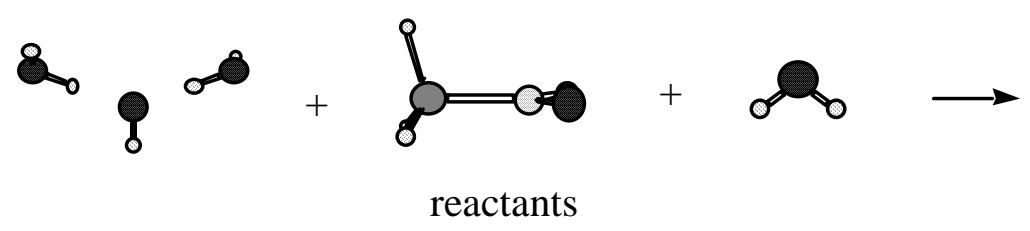

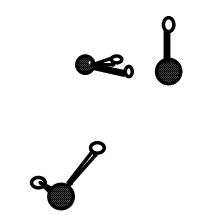

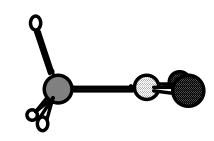

cmp1

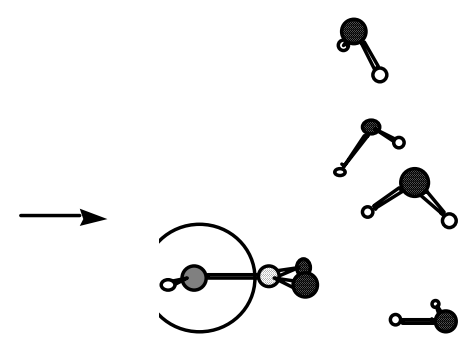

cmp2

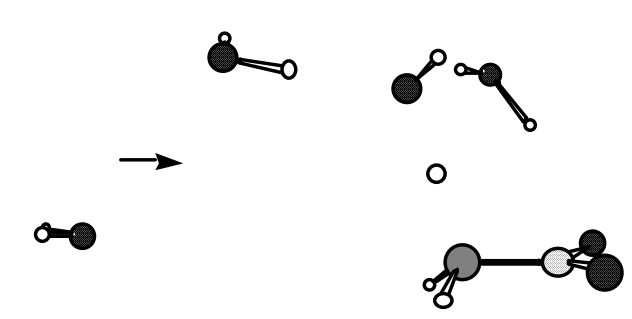

TS

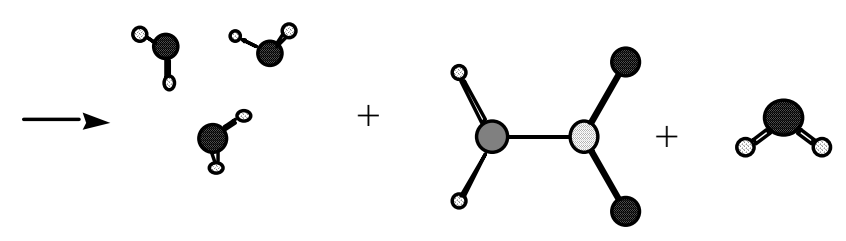

products

Figure 1. Reaction scheme for $\mathrm{CH}_{3} \mathrm{NO}_{2}+\mathrm{OH}^{-}$with the cluster model.

Calculations in the gas phase have showed that $\mathrm{CH}_{3} \mathrm{CH}_{2} \mathrm{NO}_{2}$ is relatively more acidic than $\mathrm{CH}_{3} \mathrm{NO}_{2}$, which is consistent with the experimental trend. ${ }^{7}$ Two factors have been considered to account for the higher acidity of $\mathrm{CH}_{3} \mathrm{CH}_{2} \mathrm{NO}_{2}$ than $\mathrm{CH}_{3} \mathrm{NO}_{2}$ : acid-weakening polar effect of the $\mathrm{CH}_{3}$ group in $\mathrm{CH}_{3} \mathrm{CH}_{2} \mathrm{NO}_{2}$, and hyperconjugative stabilization of nitronate ion (2), the latter being dominant. $^{2}$ The contribution of the hyperconjugative resonance structure in $\mathbf{2}$ has been demonstrated in a shorter C-C bond length (1.491 vs. $1.520 \AA$ ) and a longer C-H bond length (1.100 vs. $1.093 \AA$ ) in ethyl nitronate ion than in nitroethane. ${ }^{7}$ The gas phase calculations gave the same acidity order as in water and supported the rationalization given in the literature for the acidity difference. On the other hand, the barrier height was calculated to be lower for the reaction of $\mathrm{CH}_{3} \mathrm{CH}_{2} \mathrm{NO}_{2}$ than that of $\mathrm{CH}_{3} \mathrm{NO}_{2}$, which disagreed with the experiment. Thus, nitroalkane anomaly does not exist in the gas phase reaction. 


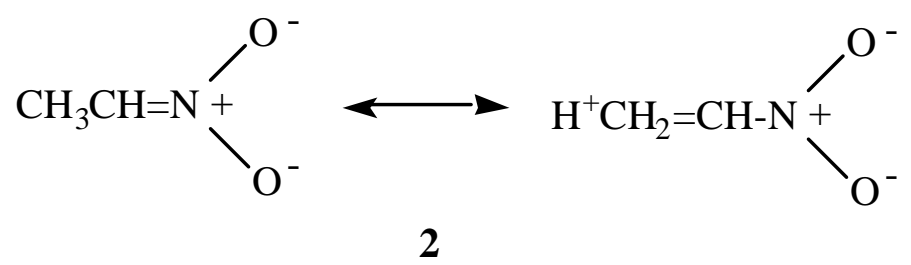

Table 1. Free energy changes for proton transfer reactions of $\mathrm{RCH}_{2} \mathrm{NO}_{2}{ }^{\mathrm{a}}$

\begin{tabular}{|c|c|c|c|c|c|}
\hline $\mathrm{RNO}_{2}$ & Method & Cmp1 & TS & Cmp2 & Products \\
\hline \multicolumn{6}{|c|}{ gas phase $\left(\mathrm{CN}^{-} \text {as a base }\right)^{\mathrm{b}}$} \\
\hline $\mathrm{CH}_{3} \mathrm{NO}_{2}$ & B3LYP $^{\mathrm{C}}$ & -6.5 & 0.4 & -7.0 & 9.3 \\
\hline $\mathrm{CH}_{3} \mathrm{CH}_{2} \mathrm{NO}_{2}$ & B3LYP $^{c}$ & -6.8 & -0.6 & -9.2 & 7.2 \\
\hline $\mathrm{CH}_{3} \mathrm{NO}_{2}$ & $\mathrm{MP}^{\mathrm{d}}$ & -7.9 & 3.5 & -3.2 & 13.2 \\
\hline \multirow[t]{2}{*}{$\mathrm{CH}_{3} \mathrm{CH}_{2} \mathrm{NO}_{2}$} & $\mathrm{MP}^{\mathrm{d}}$ & -8.7 & 2.7 & -4.0 & 11.9 \\
\hline & \multicolumn{4}{|c|}{ cluster system } & \\
\hline $\mathrm{CH}_{3} \mathrm{NO}_{2}$ & B3LYP $^{\mathrm{C}}$ & -7.0 & -5.8 & $\begin{array}{c}-13.1 \\
\end{array}$ & 6.3 \\
\hline $\mathrm{CH}_{3} \mathrm{CH}_{2} \mathrm{NO}_{2}$ & B3LYP & -7.6 & -5.1 & -16.3 & 4.2 \\
\hline $\mathrm{CH}_{3} \mathrm{NO}_{2}$ & $\mathrm{MP}^{\mathrm{d}}$ & -6.1 & -4.3 & -14.4 & 6.8 \\
\hline \multirow[t]{2}{*}{$\mathrm{CH}_{3} \mathrm{CH}_{2} \mathrm{NO}_{2}$} & $\mathrm{MP}^{\mathrm{d}}$ & -6.7 & -4.0 & -16.2 & 5.5 \\
\hline & \multicolumn{3}{|c|}{ PCM (water) } & & \\
\hline $\mathrm{CH}_{3} \mathrm{NO}_{2}$ & B3LYP $^{\mathrm{C}}$ & -0.4 & 15.1 & 1.4 & 7.9 \\
\hline $\mathrm{CH}_{3} \mathrm{CH}_{2} \mathrm{NO}_{2}$ & B3LYP & -0.2 & 17.0 & -0.6 & 6.8 \\
\hline $\mathrm{CH}_{3} \mathrm{NO}_{2}$ & $M P 2^{d}$ & -2.0 & 16.1 & 1.5 & 10.0 \\
\hline $\mathrm{CH}_{3} \mathrm{CH}_{2} \mathrm{NO}_{2}$ & $\mathrm{MP}^{\mathrm{d}}$ & -1.2 & 17.3 & -0.2 & 9.1 \\
\hline
\end{tabular}

${ }^{a}$ Relative energy vs. separated reactants in $\mathrm{kcal} \mathrm{mol}^{-1}$ at $25{ }^{\circ} \mathrm{C}$. Experimental activation and reaction energies are 16.1 and $-4.5 \mathrm{kcal} \mathrm{mol}^{-1}$ for $\mathrm{CH}_{3} \mathrm{NO}_{2}$ and 16.9 and $-7.0 \mathrm{kcal} / \mathrm{mol}$ for $\mathrm{CH}_{3} \mathrm{CH}_{2} \mathrm{NO}_{2}$, respectively (reference 2). b From reference 7. ${ }^{\mathrm{c}} \mathrm{B} 3 \mathrm{LYP} / 6-31+\mathrm{G}^{*}$. ${ }^{\mathrm{d}}$ $\mathrm{MP} 2 / 6-311+\mathrm{G}^{* *}$.

In contrast, the present calculations with the cluster model gave results, which is qualitatively consistent with experiments in solution. At both B3LYP and MP2 levels of theory, the reaction with $\mathrm{CH}_{3} \mathrm{CH}_{2} \mathrm{NO}_{2}$ is more exothermic but the barrier is higher than the reaction with $\mathrm{CH}_{3} \mathrm{NO}_{2}$. Thus, the anomaly was reproduced. The same trend was observed with the PCM model. The 
reaction energy profile calculated with the PCM model is shown in Figure 2. It is interesting to note that due to large solvation effect on the base $\left(\mathrm{OH}\left(\mathrm{H}_{2} \mathrm{O}\right)_{2}{ }^{-}\right)$, the calculated activation barriers are now positive and similar to the experimental values. The close agreement between the calculated and experimental activation barriers is fortuitous because the solvation energy of the TS is based on the cluster model, in which the base used is not solvated $\mathrm{OH}^{-}$but $\left(\mathrm{OH}\left(\mathrm{H}_{2} \mathrm{O}\right)_{2}{ }^{-}\right)$.

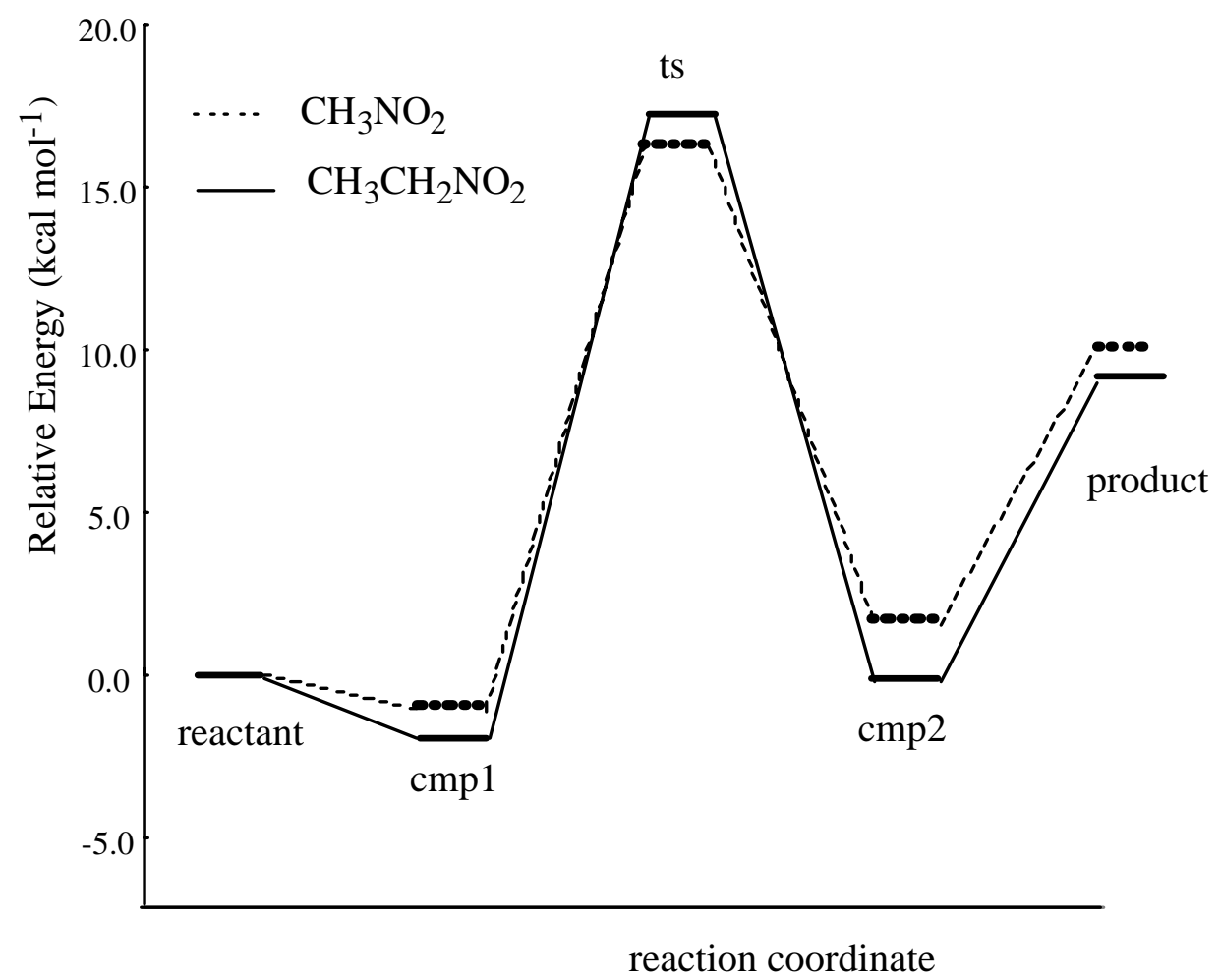

Figure 2. Energy profile for reaction 1 with the PCM model.

The most important factor proposed in the literature to account for the anomaly in water is the Coulomb interaction between the substituent and negative charge build-up on the $\alpha$-carbon at the TS. $^{2}$ It was assumed that the negative charge generated in the TS partly localized on the $\alpha$-carbon due to favorable Coulomb interaction with positively charged hydrogen in flight, whereas the negative charge is nearly perfectly localized on $\mathrm{NO}_{2}$ group in the product. Such partial charge delocalization at a TS has been noticed for the identity proton transfers by Bernasconi, ${ }^{6}$ who succeeded to show computationally that in the $\mathrm{CH}_{3} \mathrm{NO}_{2} / \mathrm{CH}_{2}=\mathrm{NO}_{2}{ }^{-}$and the $\mathrm{CH}_{3} \mathrm{CH}=\mathrm{O} / \mathrm{CH}_{2}=\mathrm{CHO}^{-}$systems the TS is imbalanced in the sense that charge delocalization into the $\pi$-electron acceptor group lags behind the proton transfer. ${ }^{10}$

The calculated charge distributions for reaction 1 are listed in Table 2. Here group charges were calculated for $\mathrm{CH}_{2}$ and $\mathrm{NO}_{2}$ substructures based on natural population analyses, and the relative amount of negative charge on $\mathrm{CH}_{2}$ vs. $\mathrm{CH}_{2} \mathrm{NO}_{2}$ is compared between the TS and the anion. For example, $\mathrm{CH}_{2} / \mathrm{CH}_{2} \mathrm{NO}_{2}=0.17$ at the cluster TS means that $17 \%$ of the negative charge 
developed on $\mathrm{CH}_{2} \mathrm{NO}_{2}$ at the TS is localized on $\mathrm{CH}_{2}$. This number is larger than the corresponding number $(0.12)$ in the anion. The difference between the TS and the anion is clearer for the PCM model. In summary, the charge delocalization lags behind the proton transfer in nitroalkane deprotonation as originally suggested by Kresge, ${ }^{2}$ which could be the origin of the anomaly observed for reaction 1.

Table 2. Group charges for stationary structures of reaction of $\mathrm{CH}_{3} \mathrm{NO}_{2}$ and $\mathrm{OH}^{-}$

\begin{tabular}{llcc}
\hline & & Cluster model $^{\mathrm{a}}$ & PCM model $^{\mathrm{b}}$ \\
\hline $\mathrm{CH}_{3} \mathrm{NO}_{2}$ & $\mathrm{H}$ & 0.27 & 0.27 \\
& $\mathrm{CH}_{2}$ & -0.01 & -0.06 \\
& $\mathrm{NO}_{2}$ & -0.26 & -0.33 \\
\hline $\mathrm{TS}$ & $\mathrm{H}$ & 0.39 & 0.49 \\
& $\mathrm{CH}_{2}$ & -0.10 & -0.17 \\
& $\mathrm{NO}_{2}$ & -0.50 & -0.47 \\
& $\mathrm{CH}_{2} / \mathrm{CH}_{2} \mathrm{NO}_{2}$ & 0.17 & 0.26 \\
& & \\
\hline $\mathrm{CH}_{2} \mathrm{NO}_{2}$ anion & $\mathrm{CH}_{2}$ & -0.12 & 0.06 \\
& $\mathrm{NO}_{2}$ & -0.88 & -1.06 \\
& $\mathrm{CH}_{2} / \mathrm{CH}_{2} \mathrm{NO}_{2}$ & 0.12 & 0.00 \\
& & \\
\hline
\end{tabular}

${ }^{\text {a }}$ At B3LYP/6-31+G*. ${ }^{\text {b }}$ At HF/6-31+G*.

\section{Reaction of $\mathrm{ArCH}_{2} \mathrm{NO}_{2}$}

As in the case of reaction 1, the reaction of $\mathrm{ArCH}_{2} \mathrm{NO}_{2}$ also exhibits a double-well profile, and we will focus on the reaction and activation energies. In contrast to the reactions of $\mathrm{CH}_{3} \mathrm{NO}_{2} / \mathrm{CH}_{3} \mathrm{CH}_{2} \mathrm{NO}_{2}$, where nitroalkane anomaly was reproduced by calculations, the reaction of $\mathrm{ArCH}_{2} \mathrm{NO}_{2}$ showed no anomaly even with the PCM model. The calculated Brønsted plots for the cluster system and the PCM model are illustrated in Figures 3A and 3B. It can be seen that the electron-withdrawing substituent $\left(p-\mathrm{NO}_{2}\right)$ stabilizes both the TS and the anion, and the effect is larger on the product anion state, giving the Brønsted $\alpha$ of 0.38 with the cluster model. This is smaller than the value (0.51) observed previously for the gas phase reaction. ${ }^{7}$ The coefficient $\alpha$ became even smaller for the PCM model. The population analyses in Table 3, however, clearly indicate the existence of the charge imbalance at the TS. In summary, although TS imbalance exists, it does not induce anomaly for the reaction of $\mathrm{ArCH}_{2} \mathrm{NO}_{2}$ with $\mathrm{OH}^{-}$. Factors that were not taken into account in the present study must play important role in the anomaly. One of such factors could be dynamic asynchronicity of the reaction, in which two reaction events, proton transfer and rehybridization in the present case, occur in different time scales dynamically. ${ }^{11}$ 


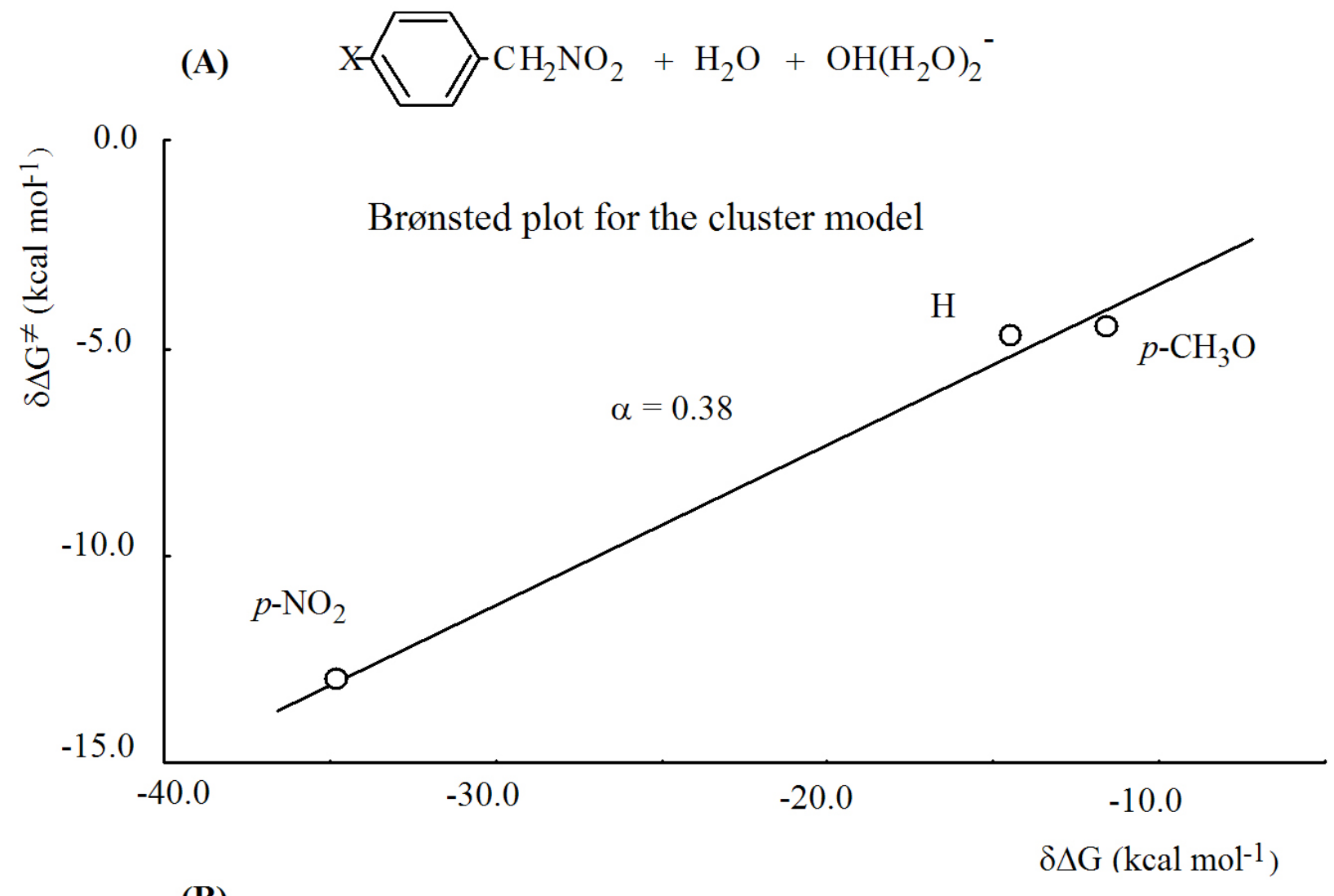

(B)

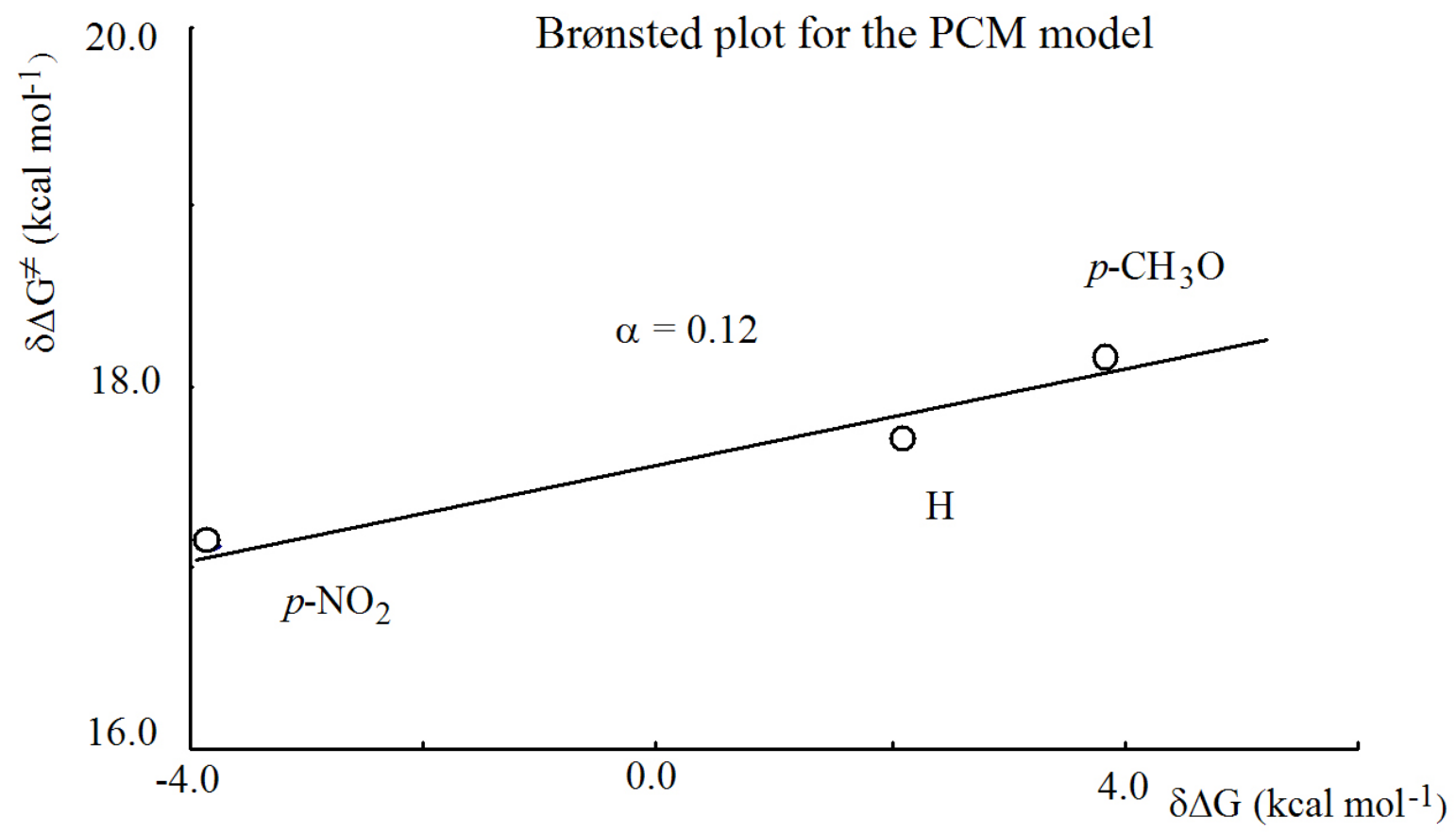

Figure 3. Brønsted plots for reaction 2 calculated for (A) the cluster model and (B) the PCM model. 
Table 3. Group charges for stationary structures of reaction of $\mathrm{PhCH}_{2} \mathrm{NO}_{2}$ and $\mathrm{OH}^{-\mathrm{a}}$

\begin{tabular}{llcc}
\hline & & cluster model $^{\mathrm{b}}$ & PCM model $^{\mathrm{c}}$ \\
\hline $\mathrm{PhCH}_{2} \mathrm{NO}_{2}$ & $\mathrm{H}$ & 0.24 & 0.31 \\
& $\mathrm{CH}$ & -0.53 & -0.45 \\
& $\mathrm{NO}_{2}$ & -0.20 & -0.28 \\
& & & \\
\hline $\mathrm{TS}$ & $\mathrm{H}$ & 0.43 & 0.50 \\
& $\mathrm{CH}$ & -0.63 & -0.51 \\
& $\mathrm{NO} 2$ & -0.41 & -0.49 \\
& $\mathrm{CH} / \mathrm{CHNO}_{2}$ & 0.60 & 0.51 \\
& & & -0.38 \\
\hline $\mathrm{PhCHNO} 2$ & $\mathrm{CH}$ & -0.57 & -0.96 \\
anion & $\mathrm{NO}_{2}$ & -0.77 & 0.28 \\
& $\mathrm{CH} / \mathrm{CHNO}_{2}$ & 0.43 & \\
\hline
\end{tabular}

${ }^{\text {a }}$ Based on Mulliken charges. ${ }^{\text {b }}$ At B3LYP/6-31+G*. ${ }^{\text {c }}$ At HF/6-31+G*.

\section{Conclusions}

The present calculations revealed that nitroalkane anomaly could be reproduced for the deprotonation reactions of $\mathrm{CH}_{3} \mathrm{NO}_{2} / \mathrm{CH}_{3} \mathrm{CH}_{2} \mathrm{NO}_{2}$ with the cluster and the PCM models, and that the TS imbalance indeed exists in the reactions. In contrast, for the reactions of $\mathrm{ArCH}_{2} \mathrm{NO}_{2}$ the charge delocalization lags behind proton transfer, which, however, does not cause anomaly. Judging from the small $\alpha$ values and the charge imbalance observed with the cluster and the PCM models, the nitroalkane anomaly for $\mathrm{ArCH}_{2} \mathrm{NO}_{2}$ may not be totally due to an intrinsic character of TS as has been assumed, but may be related to some other factors such as reaction dynamics.

\section{Acknowledgements}

Numerical calculations were in part carried out at Research Center for Computational Science, Okazaki, Japan. The study was supported by the Grant-in-Aid for Scientific Research from the Ministry of Education, Culture, Sports, Science and Technology, Japan. SCA thanks Japan Society for the Promotion of Science for a fellowship. 


\section{References}

1. Pearson, R. G.; Dillon, R. L. J. Am. Chem. Soc. 1953, 75, 2439.

2. Kresge, A. J. Can. J. Chem. 1974, 52, 1897. Kresge, A. J.; Drake, D. A.; Chang, Y. Can. J. Chem. 1974, 52, 1889.

3. Bordwell, F. G.; Boyle, W. J. Jr. J. Am. Chem. Soc. 1971, 93, 511. ibid. 1972, 94, 3907. Bordwell, F. G.; Boyle, W. J. Jr.; Yee, K. C. J. Am. Chem. Soc. 1970, 92, 5926. Exner, O; Krygowski, T. M. Chem. Soc. Rev. 1996, 25, 71.

4. Richard, J. P.; Williams, G.; Gao, J. J. Am. Chem. Soc. 1999, 121, 715.

5. Grinblat, J.; Ben-Zion, M.; Hoz, S. J. Am. Chem. Soc. 2001, 123, 10738. Eliad, L.; Hoz, S. J. Phys. Org. Chem. 2002, 15, 540.

6. (a) Bernasconi, C. F. Adv. Phys. Org. Chem. 1992, 27, 116. (b) Bernasconi, C. F. Acc. Chem. Res. 1992, 25, 9.

7. Yamataka, H.; Mustanir; Mishima, M. J. Am. Chem. Soc. 1999, 121, 10223.

8. Gaussian 98, Revision A.6, Frisch, M. J.; Trucks, G. W.; Schlegel, H. B.; Scuseria, G. E.; Robb, M. A.; Cheeseman, J. R.; Zakrzewski, V. G.; Montgomery, Jr., J. A.; Stratmann, R. E.; Burant, J. C.; Dapprich, S.; Millam, J. M.;. Daniels, A. D; Kudin, K. N.; Strain, M. C.; Farkas, O.; Tomasi, V.; Barone, M.; Cossi, R.; Cammi, B.; Mennucci, C.; Pomelli, C.; Adamo, S.; Clifford, J.; Ochterski, J.; Petersson, G. A.; Ayala, P. Y.; Cui, Q.; Morokuma, K.; Malick, D. K.; Rabuck, A. D.; Raghavachari, K.; Foresman, J. B.; Cioslowski, J.; Ortiz, J. V.; Stefanov, B. B.; Liu, G.; Liashenko, A.; Piskorz, P.; Komaromi, I.; Gomperts, R.; Martin, R. L.; Fox, D. J.; Keith, T.; Al-Laham, M. A.; Peng, C. Y.; Nanayakkara, A.; Gonzalez, C.; Challacombe, M.; Gill, P. M. W. ; Johnson, B.; Chen, W.; Wong, M. W.; Andres, J. L.; Gonzalez, C.; Head-Gordon, M.; Replogle, E. S.; Pople, J. A. Gaussian, Inc., Pittsburgh PA, 1998.

9. (a) PCM Cossi, M.; Baron, V.; Cammi, R.; Tomasi, J. Chem. Phys. Lett. 1996, 255, 327. (b) Baron, V.; Cossi, M.; Tomasi, J. J. Chem. Phys. 1997, 107, 3210.

10. Bernasconi, C. F.; Wenzel, P. J. J. Org. Chem. 2001, 66, 968, and references cited therein. 11. Ammal, S.C.; Yamataka, H.; Aida, M.; Dupuis, M. Science 2003, 99, 1555. 